\title{
Factors affecting Post-retirement Satisfaction of Community-Dwelling
}

\section{Older Adults}

\author{
Manal Mohammed Abdel Moniem Hawash, Lecturer \\ Gerontological Nursing, Faculty of Nursing, Alexandria University \\ Marwa Ibrahim Mahfouz Khalil, Lecturer \\ Gerontological Nursing, Faculty of Nursing, Alexandria University
}

\begin{abstract}
Retirement is a potentially dramatic life transition in later adulthood as it indicates that the individual just begins to be old. It is usually associated with many physical, psychological and social changes. Retirement satisfaction is extremely influenced by availability of convenient resources. Objective: The aim of the study is to determine factors affecting postretirement satisfaction of community-dwelling older adults. Setting: The current study executed in at outpatient clinics of two hospitals; Gamal Abdel-Nasser and Farouk hospitals in Alexandria. Subjects: Participants eligible for inclusion in the study were 210 retirees of 60 to 85 years of age, retired from full-time paid work, and able to communicate effectively. Tools: Three tools were used for data collection; Sociodemographic and clinical structured interview schedule, Retirement Satisfaction Inventory and Retirement Resources Inventory. Results: The result of existing study showed that $49.0 \%$ of the studied sample expressed low satisfaction level with the current life circumstances post - retirement and $68.1 \%$ of them had low overall retirement resources. Conclusion: High satisfaction level is significantly correlated to the high level of global resources. The most rife factors associated with higher satisfaction degree with life post-retirement were the retirees' age, sex, marital status, level of education, occupation before retirement, income, absence of chronic illnesses, ability to accomplish various activities of daily living, and pre-retirement planning. Additional significant relationship was found between satisfaction of the retired older adults with life and the inclusive domains of their lifestyle pattern. Recommendations: Constant delineation and application of pre-retirement planning programs should be done. All variables that contribute to post-retirement satisfaction; particularly supported retirement resources; should be assessed continuously during retirement experience period.
\end{abstract}

Kevwords: Post-retirement satisfaction; Retired older adults; Retirement resources.

\section{Introduction}

The concept of retirement is increasingly multifaceted with no consensus on a satisfactory definition of retirement. Rather, it is a unrivaled event of permanent withdrawal from working life ${ }^{(1)}$. Retirement also encompasses different meanings to older adults' wellbeing; in which retirement is experienced differently either positively or negatively. Some retirees tend to view retirement as an occasion to relinquish unrewarding responsibilities in the pursuit of new goals, interests, and activities, while others evaluate undesired forced retirement as a source of provoking stress, rapid physical deterioration, and depression ${ }^{(2)}$. The efficacious and spirited inwardness of retirement transition is multidimensional. It is a longitudinal individualistic process during which retirees' level of wellbeing tend to diverge in response to their social ties, adjustment strategies to the loss of work role, and the development of a satisfactory post-retirement lifestyle ${ }^{(3)}$. Therefore, adjustment and satisfaction to retirement are related, but not identical. Adjustment problems arise from pre-retirement anxiety about consequences of retirement, while retirement satisfaction is primarily related to the individual's access to key resources such as finance, health, and the marital and social relationship $^{(4)}$.

Retirement often has a huge impact on elders' social relationships. For some retired elders, retirement may not live up to their 
social expectations, and therefore may cause difficulties in their social life. In a converse, retirement could allow extra time for family activities and involvement; take usefulness of more social participation in community assemblage which may even be an incentive for retiring among others (5). Psychologically, fixed age of retirement can disregard the possible desire of older adults to continue working in the labor force which enforces the feeling of uncertainty and confusion. This period of emotional transition usually continue from six to eighteen months for the person to accustom of this new territory ${ }^{(6)}$. In contrast, retirement period may release years of work stress and give up of job responsibilities to be replaced by a beginning of new directed valued activity and embark real change in a more satisfying manner ${ }^{(7)}$. Maintenance of faith in God and religious activities among retirees build acceptance and more realistic expectations into their daily life pattern and help them to combat loneliness ${ }^{(8)}$.

For many retirees, retirement transition is associated with change in postretirement life style pattern. As body efficiency declines during the transition from employment to retirement in addition to age-related effects on vision, reaction time, coordination and cognitive response, all these changes might hinder retirees' ADLs and functional abilities ${ }^{(9)}$. Weight gain is expected after occupational retirement unless retired older adults decrease their calories intake and substitute their workrelated physical activity with other activities $^{(10)}$. Retirement could also influence retirees' sleeping pattern and cause changes in schedule and activities as it is no longer necessary to get a sufficient night's sleep hours to be prepared for next days' efforts $^{(11)}$.

According to Van-Solinge and Henkens $(2008)^{(12)}$, satisfaction during the retirement transition implies "the level of contentment one has with his or her life in retirement", and distils on the way older adults adapt to the role change and identity loss which entails crisis or perspectives continuity. Crisis notion lies on the presumption that the occupational role is the cornerstone, around it all roles revolve, and therefore, retirement wellbeing and adjustment will not be achieved unless substituted with other meaningful activities. Contrariwise, pursuant to the perspective continuity; retirement is judged as a legitimate and ordinary role in the entire society; hence achievement of high selfesteem and identity stemmed from other roles in order to fill the gap created by occupational retirement. The pattern of postretirement satisfaction generally changes across time and focuses on different assets of resources which facilitate role substitution after the retraction from labor force ${ }^{(13)}$.

Retirement resources refer to "those resources that are crucial for the retirees to structure their retirement lives and pertaining to their retirement wellbeing and satisfaction"(14). Physical health, financial and social resources are categorized as the most labeled resources needed in the retirement context among older adults ${ }^{(15)}$. Physical health resources is conceptualized into the frame of being continuously energetic and motivated to engage in physical activities and pay active efforts to manage daily demands. Lack of financial resources induce dependency and correlates negatively with the ease of post-retirement satisfaction and well-being ${ }^{(16)}$. Emotion intelligence, which encompasses the elders' ability to intervene emotions, is also a resource used to manage psychological stressors taxing the older adults' coping capacity to retirement ${ }^{(17)}$. Leisure engagement is a reference of social sources and activities that are predicted to achieve retirement satisfaction ${ }^{(18)}$. Furthermore, the importance of using adaptive and positive cognitive resources are all indices of retirement wellbeing and satisfaction for maintaining normal self-esteem, mastery of self-efficacy, and optimism ${ }^{(19)}$.

The gerontological nurses have a unique position that helps retirees to realize 
that with pre-retirement planning, and supportive retirement resources, retirees can live meaningful independent lives ${ }^{(20)}$. They have also a vital role to build on the strengths of the individual's life experiences and coping expertness in order to develop meaningful ways for adjustment and satisfaction during the transference from the work role ${ }^{(21)}$. As well, they have an opportunity to carry out counseling for older adults regarding the realities of retirement in order to assist retirees to achieve retirement satisfaction and wellbeing ${ }^{(22)}$. Despite the magnitude of the retirement transmission, unfortunately few studies were found to explore the impact of the retirement experience over time on the older adults' wellbeing and satisfaction ${ }^{(2,23)}$. Because of consistent individual differences in how retirement is experienced over time; therefore, there is a need for scientific researches to investigate the relationship between elders' retirement satisfaction and the antecedents of retirement well-being.

\section{Aim of the Study}

The study aims to determine the factors affecting post-retirement satisfaction of community-dwelling older adults.

\section{Research Question:}

What are the factors that affect postretirement satisfaction among communitydwelling older adults?

\section{Materials and Method}

\section{Materials}

Design: This study followed a descriptive correlational research design.

Setting: This study was conducted in Alexandria in two settings: The outpatient clinics of both the Health Insurance clinic (Gamal Abdel Nasser Hospital) and the Ophthalmology General Hospital (Farouk) affiliated to the Ministry of Health.

Subjects: The study subjects comprised 210 retired community-dwelling older adults who attended the above mentioned settings, and fulfilling the following criteria: age 60 years old and above, retired from full-time paid work for a period of at least 6months "a period needed for either the disenchantment stage or reorientation phase to occur postretirement i.e dissatisfaction or satisfaction", and able to communicate effectively.

The program Epi info 7 was used to estimate the sample size based on using $5 \%$ possible error and the confidence coefficient $97 \%$ which revealed the minimum sample size to be 210 retired older adults.

Tools: Three tools were used to collect the necessary data:

Tool I: Retired older adult's sociodemographic and clinical data structured interview schedule

This tool was developed by the researchers based on relevant literature to collect the following information from the study subjects:

Part I "Socio-demographic data of the retired elders" such as age, sex, marital status, educational level, occupation priorretirement, post retirement occupation if found, current financial status, and available family/social support.

Part II "Clinical data" such as the presence of medical problems (either pre or post retirement), treatment regimen, reason and frequency of previous hospitalization in the last year, and frequency of clinic visits.

Part III "Data about previous and postretirement job" such as retirement age, causes of early retirement if found, satisfaction with previous occupation, preparation for retirement, and last job assumed.

Part IV "Life style pattern of older adults after retirement": such as, diet, exercise and sleep pattern, participation in activities such as physical activities, community services, recreational activities, religious/spiritual activities, financial affairs, membership in sport/social club, and socializing with family and friends. 


\section{Tool II: Retirement Satisfaction $\underline{\text { Inventory (RSI) }}$}

This scale was developed by Floyd et al $(1992)^{(24)}$. It is an open-ended questionnaire in which the retired participant is asked to rate his/her degree of satisfaction regarding a specific area of retirement: married life, financial situation, physical health, spouse's health, quality of residence, relationships with other family members, level of physical activity, access to transportation, services for government aid programs, and personal safety. The reliability of the tool was tested $(\mathrm{r}=0.86)$ and answer of study subjects were finally categorized into a four points Likert scale where three (3) indicated "Satisfied ", two (2) indicated "to Somewhat Satisfied", one (1) indicated "Dissatisfied" and zero (0) indicated "Not Applicable". The total score of retired participants' responses were categorized as follows: a score of less than 16 indicated low satisfaction level with life, a score from 16 to 24 indicated moderate satisfaction level and a score from 25 to 33 indicated high satisfaction level.

\section{Tool III: Retirement Resources Inventory $\underline{(\mathbf{R R I})}$}

The 35-item categorized Inventory, RRI, is a self-determination measurement developed by Leung C \& Earl J (2012) ${ }^{(17)}$ to assess availability of supported resources during the retiring period reflected on the whole retirement well-being. It is a longgoaled assessment of the future retirement plan and provide the retired participants with a design frame of needed retirement interventions. It also determine individualized well-tailored retirement management in case of resource deficits. RRI was symbolized by a three-scaled factors. The three domains involved resource items were: RT3 (physical and financial), RT2 (social), and RT1 (emotional, cognitive and motivational) resources types. Standardized 5-point Likert scales with appropriate anchors were used for each question. Items 2, 3, 22, 24, 34, 35 were scored in the opposite order as they are a reverse items. Overall scores ranged from
1 to 175 , with higher scores representing higher levels of resources available and subsequently greater level of retirement wellbeing.

\section{Method}

- Official letters were issued from the Faculty of Nursing, Alexandria University and forwarded to the hospital responsible authority of Alexandria Health Insurance clinic (Gamal Abdel Nasser Hospital) and Alexandria Ophthalmology General Hospital (Farouk) to obtain their approval to carry out the study.

- The director of each of the setting was informed about the purpose of the study and time of starting the data collection.

- Tool I (socio-demographic and clinical data structured interview schedule) was developed by the researchers after a thorough review of literature. Tools II and III were translated into Arabic language by the researchers, and tested for validity and reliability. The content validity of the tools was tested by a jury of 7 experts in the related fields of Gerontological Nursing, Medical Surgical Nursing, Nursing Education, Community Health Nursing and Psychiatric and Mental Health Nursing. The required modifications were carried out accordingly.

- Tools II and III were tested for their reliability using test-retest reliability. The tools were applied on 20 retired elders from El Montaza Health Insurance outpatient clinics. These were not included in the study sample. These scales were applied again on the same retired older adults after two weeks. The Retirement Satisfaction Inventory and Retirement Resources Inventory had reliabilities of $r=0.86$, and 0.88 respectively. 
- A pilot study was carried out on five (21) retired older adults selected from El Montaza Health Insurance outpatient clinics to assess the applicability, clarity and feasibility of the study tools, and to determine also the estimated time to finalize the study tools. These were not included in the study sample. In accordance with pilot study findings, the needed and appropriate modifications were done. Then the tools were into their final form.

- The researchers used to attend the selected clinics from 9.00 am to $2 \mathrm{pm}$ on all working days of the week. i.e. from Saturday through Thursday to identify those fulfilling study criteria.

- Each study subject was interviewed individually by the researchers in the waiting area of the clinic while sitting comfortably, the researchers explained the purpose of the study in order to gain the elders' cooperation, then the necessary data was collected. It took nearly 20-30 minutes to complete the sheets.

- Collection of data covered a period of 3 months from the beginning of September to the end of November 2016.

\section{Ethical considerations:}

An informed consent from elders to participate in the study was obtained after explanation of the study purpose and its potential benefits. Privacy/ anonymity and confidentiality of the collected data was maintained.

\section{Statistical Analysis}

Data were fed to the computer and analyzed using IBM SPSS software package version 20.0. Qualitative data were described using number and percent. Quantitative data were described using range (minimum and maximum), mean, standard deviation, Student t-test, F-test (ANOVA) and Pearson coefficient. Significance of the obtained results was judged at the $5 \%$ level.

\section{Results}

Table (1) shows the socio-demographic characteristics of the retired older adults and its relation to their life satisfaction postretirement. The table illustrates that the highest mean score $(57.34 \pm 15.28)$ of life satisfaction is obtained by young old than the middle old. The difference is statistically significant $\left(\mathrm{t}=16.074^{*}, \mathrm{p}<0.001^{*}\right)$.

Regarding sex, higher life satisfaction level is obtained by males $(59.95 \pm 24.05)$ than females $(42.10 \pm 14.86)$, the variance is statistically significant $\left(\mathrm{t}=6.482^{*}, \mathrm{p}<0.001^{*}\right)$. The same is observed for different categories of marital status, where the difference in life satisfaction between married and unmarried is statistically significant $\left.\mathrm{t}=14.884^{*}, \mathrm{p}<0.001^{*}\right)$. As regards the level of education, the highest life satisfaction mean score $(90.91 \pm 9.46)$ is obtained by those with higher level of education. The difference is statistically significant ( $\left.\mathrm{t}=16.729^{*}, \mathrm{p}<0.001^{*}\right)$. Moreover, high life satisfaction level is observed among employers $(60.04 \pm 22.56)$ when differentiated from workers $(39.66 \pm 14.51)$. The difference is statistically significant $\left(\mathrm{t}=7.933^{*}, \mathrm{p}<0.001^{*}\right)$.

Income, presence of chronic diseases, and ability to perform various activities of daily living are significantly correlated to the life satisfaction. Older adults who reported more life satisfaction level are those with enough income $(77.93 \pm 16.77)$, absence of chronic illnesses $(90.34 \pm 8.66)$, and able to perform different activities of daily livings $(62.87 \pm 20.14)$. The differences are statistically significant. The same picture is noticed regarding the presence of preretirement plan where the older adults who planned previously for the retirement had higher mean scoring life satisfaction level $(74.63 \pm 15.60)$ compared to those who didn't (39.35 \pm 13.49$)$. The difference is statistically significant. 
Table (2) determines the various postretirement resources of the retired older adults. The table shows that $68.1 \%$ of the retirees reported having low overall resources compared to only $13.8 \%$ with high resources with total mean score 89.94 \pm 33.53 . Emotional, cognitive and motivational resources show the highest resources reported by the retired older adults (total mean score of $48.50 \pm 19.13$ ), followed by social resources where the total mean score is $21.88 \pm 8.97$ while physical and financial resources came the least reported (total mean score is 19.56 \pm 7.66 ). The difference between resource subcategories are statistically significant $\left(\mathrm{p}<0.001^{*}\right)$.

Table (3) shows the relation between availability of resources (physical and financial, social, emotional, cognitive and motivational) and post-retirement life satisfaction. The table illustrates that high level of life satisfaction is significantly correlated with the high availability of overall resources $\left(\mathrm{F}=257.752^{*}, \mathrm{p}<0.001^{*}\right)$. Also, the table illustrates a significant relation with the various resource subdomains, where the highly satisfied retired older adults obtained higher mean levels of physical and financial resources $(91.69 \pm 5.42)$, social resources $(89.70 \pm 8.54)$, and emotional, cognitive and motivational resources $(87.88 \pm 12.48)$. The difference is statistically significant $\quad\left[\left(\mathrm{F}=210.297^{*}\right.\right.$, $\left.\mathrm{p}<0.001^{*}\right), \quad\left(\mathrm{F}=154.993^{*}, \quad \mathrm{p}<0.001^{*}\right), \quad$ and $\left.\mathrm{F}=534.859, \mathrm{p}<0.001^{*}\right)$ respectively].

Table (4) reflects the level of life satisfaction among retired older adults. Nearly half of them $(49.0 \%)$ expressed low level of satisfaction with the current life circumstances, compared with only $15.2 \%$ who reported being highly satisfied. The total mean score is $16.87 \pm 7.23$ with $11 \pm 21.89$ of the mean percent score of the total scale subcategories.

Table (5) shows the relation between lifestyle pattern of retired older adults and post retirement life-satisfaction. According to this table, there is a positive significant correlation between the overall domains of the lifestyle pattern and life satisfaction of the retired older adults (Pearson coefficient $\left.=0.879^{*}, \quad \mathrm{p}<0.001^{*}\right)$. Also, a positive significant correlation was observed between each sub- domains of the lifestyle pattern and life satisfaction of the retired older adults: either physical functioning $\left(\mathrm{r}=0.834^{*}, \quad \mathrm{p}<0.001^{*}\right)$, social $\quad\left(\mathrm{r}=0.854^{*}\right.$, $\left.\mathrm{p}<0.001^{*}\right)$, economic $\left(\mathrm{r}=0.663^{*}, \mathrm{p}<0.001^{*}\right)$, psychological $\left(\mathrm{r}=0.783^{*}, \mathrm{p}<0.001^{*}\right)$, spiritual $\left(\mathrm{r}=0.227^{*}, \quad \mathrm{p}=0.001^{*}\right), \quad$ or recreational/ motivational $\left(\mathrm{r}=0.817^{*}, \mathrm{p}<0.001^{*}\right)$.

\section{Discussion}

Retirement satisfaction is complex and is affected by many factors such as available resources for the retired older adults, their life-style pattern, socio-demographic, clinical data, and pre-retirement planning. Collectively, the aim of any short or longterm goal toward retirement satisfaction is to feel meaning in life and not just adding years to retirees' lives ${ }^{(25)}$. This study aimed to determine the factors affecting postretirement satisfaction of communitydwelling older adults.

The results of this study proved the hypothesis underlined in the present research where a significant positive correlation was observed between the availability of multiple resources relevant to the retirement wellbeing and the degree of post-retirement satisfaction among community-dwelling retirees (table 3 ). This may be explained by the fact that having adequate resources particularly physical, financial and social help the older adults to be secure and to adjust and cope with retirement resources. For elders who left the workforce, availability of resources may be the only feasible strategy for dealing with the seemingly insoluble problems of retirement and is the main shelter when other alternatives cannot be available. In addition, satisfaction with retirement can be stressful, commands a new routine, and requires an entirely new repertoire for its reinforcement. Here comes the role of the family and social network to help older adults to adjust to 
retirement and plan new roles and engage in new lifestyle measures such as leisure and recreational activities.

None of the reviewed articles contradicted the study findings, they confirmed that the presence of paramount resources strongly contribute to successful aging, better wellbeing and raising postretirement satisfaction. Siguaw et al $(2016)^{(26)}$, Heaven et al $(2016)^{(15)}$ and Topa et al $(2017)^{(14)}$ reported, a significant effect of rejoiced resources on retirees' satisfaction with life. Also the study of Fadila and Alam $(2016)^{(27)}$ in Egypt added that adequate resources are associated with better adjustment to retirement.

Emotional, cognitive and motivational resources show the highest mean score of the resources obtained by the retired older adults compared with the social, physical and financial ones (table 2). The lied fact is that retirement is socially considered as an axle period of retirees' life in managing emotions, in which elders can substitute work loss by extending their social networks and replace some role loss by grand parenting ones that enhance general wellbeing. Retired elders are no longer bounded to the restricted work' roles and regulations or being confined to certain policies and practices which are usually converted into bursts of worry and mood instability, part of which is due to anxiety introverted from burden of work responsibility. Motivational activities can alternate or change the daily routine of retired elders and help them adjust goals to the current life circumstances and successfully impact cognitive function and self esteem. In agreement to the present study perspective (table 2), the groundbreaking work of Barnett et al $(2012)^{(28)}$ and $(2014)^{(29)}$ benefited tremendously the area of relationship between different domains of activities and the transition to retirement suggested an improvement in practicing recreational activity post-retirement. An Australian study $(2016)^{(30)}$ and a Japanese one $(2017)^{(31)}$ confirmed that the most remarkable impact of retirement was noticed on leisure time, cognitive and emotional resources, reversed actively on elders' satisfaction. Contrary, Denier et al (2017) $)^{(32)}$ and Bonsang et al $(2012)^{(33)}$ claimed a negative effect of retirement on elders' domains of cognition.

Among the most depleted resources, physical resources ranked first (table 2) and is significantly correlated with satisfaction (table 3 ). This is primarily because physical disabilities and chronic morbidities devastate the elders' health and general satisfaction. Also, the presence of chronic diseases and inability to perform various activities of daily living have often emerged as correlate of low satisfaction to retirement (table 1). Acute and chronic illnesses incorporated to physical resources inadequacy via pathologic changes associated with the underlying disease by interfering with energy production and neurologic control of mobility. Stenholm and Vahtera $(2017)^{(7)}$ identified a reduced health - related quality of life in elders during the period of transition into retirement. Byles et al $(2016)^{(34)}$ found retirement to be significantly associated with a $25 \%$ increase in physical dysfunction scores for men and a $17 \%$ increase for women. David et al $(2008)^{(35)}$ noted that retirement was associated with a 5- 14\% increase in difficulties with mobility and daily activities. By contrast, Regan et al $(2016)^{(36)}$ over scored the importance of retirement in providing more opportunities for being physically active. McDonald et al $(2015)^{(37)}$ explored an inconsistent health effect of retirement which tends to be changed over time.

Further, elders' economic situation can be another resource that affects positively life satisfaction. Chronic financial strain and hardship and poor satisfaction are interrelated. Lack of financial resources may affect the quality of shelter, nutrition, household assistance, and acquisition of needed medical care and therapeutic regimen post-retirement. The present study 
results proved that adequate financial resource decreases economic problems following retirement and is linked positively with satisfaction (table 3). The reason of any persistent dissatisfaction may be attributed to the fact that older adults who were faced with post-retirement financial difficulties may become more dependent on their family members, or others for financial support. This situation may affect their role and decrease their satisfaction. The same was reported by Brady $(2010)^{(38)}$ who concurred that having adequate income is considered the most valued and key resource possessed as it helps to fulfill life needs.

The other notable finding of this research is the positive association between domains of life style pattern and better satisfaction (table 5). Ding et al (2016) ${ }^{(39)}$ reported that changed life-style healthy behaviors upon retirement could act as a remarkable ingredient shaped the health affection. Most elders believe that religious practice is a source of great strength and a compensatory activity for role loss and fellow worshipers from a network for socialization after retirement. This finding is in agreement with the results of Lowis et al $(2009)^{(40)}$ where the retirees spend their leisure time in religious activities. The study findings also revealed that, while financial preparedness is necessary for retirement success, psychological, mental and social life-style factors are also important (table 5). The same was reported by Social Security Administration $(2011)^{(41)}$. The study of Potocnik et al $(2013)^{(42)}$ in Spain reported that the lowest retirement satisfaction level is associated with lower levels of psychosocial wellbeing. Mezuk et al $(2017)^{(43)}$ found that religious behaviors endorsed as one of the most frequently stress-coping strategies used for self regulation and life satisfaction by the retired older adults.

Retirement satisfaction is affected by age, sex, marital status, level of education, occupation before retirement, income, chronic diseases, ability to perform activities of daily living and planning during the preretirement stage (table 1). This is in accordance with the studies of Saeed and Bokharey (2016) $)^{(44)}$ and Gaied $(2014)^{(21)}$ done in Egypt. The present study also revealed a positive relationship between age and the level of the overall satisfaction to retirement (table 1) where young - old retired older adults (60 years to less than 75 years) reported higher level of satisfaction than those 75 years and more. This is because advanced age is usually associated with limitations in self-care, decreased ability to perform basic tasks, and conversely lower physical resources affects the overall satisfaction. This is in agreement with Alavinia and Burdorf $(2008)^{(45)}$, who reported that retired elders had generally underscored physical resources and less acute senses with increasing age which increase their dependence on others and decrease their satisfaction.

The present study revealed that males reported high level of overall satisfaction to retirement than females, and the difference between both sexes was statistically significant (table 1). Unlike women, men establish deeper and stronger social networks with their workmates, they became consequently more involved in social life thereafter as a result of the continuity of work-related contacts. Older women are the primary target for abusing and violence, more financially dependent, and have decreased physical strength. Bajalia $(2017)^{(46)}$ and Mary et al in Malaysia $(2016)^{(47)}$ reported that women were much more concerned about financial security and more likely to retire in response to family needs. Contrary to this result, USA Insurance and Annuity Association $(2016)^{(48)}$ reported that the retired women were more satisfied than the retired men through playing multiple volunteer roles in the society, spend time and socialize with family and friends, and participate more in religious activity which help them to cope better with retirement than males. Kubicek et al $(2011)^{(49)}$ reported that retirement may be challenging for many retired male who 
lost the role of primary family provider in addition to the work role that contributes to the risk of boredom, sense of purposelessness and inadequacy, depression and other health problems.

Retirement changes the dynamics of family relationships. An important finding of this study is that a higher percentage of the retired older adults who are married reported higher level of the overall satisfaction to retirement than the unmarried ones (table 1). This finding could be explained by the fact that married retired subjects have many family obligations that fulfill their free time. Also, the retired couples have more time to spend together and to share things they were unable to do together previously along the working years. In addition, sharing leisure activities with a spouse enhances life satisfaction during retirement. This result is in line with findings of a study done in USA by Kerr and Armstrong (2011) $)^{(50)}$ who added that unmarried retired persons tend to save less for retirement than retired married couples and thereby, the married couples were more satisfied with retirement. However, this finding is in opposition with a study done by Bozoglan (2015) ${ }^{(51)}$ which documented that the presence of the retired spouse around the house all the time is very discommoding and stressful which result in frustration and maladjustment to retirement and only $19 \%$ of women were satisfied with her marriage in their spousal retirement period.

Significant interaction between education and satisfaction emerged in this study (table 1), indicating the beneficial impact of education among retirees on their post-retirement satisfaction when compared with their non-educated counterparts. Indeed, education is considered a unique resource for retirees' life satisfaction because it provides them with certain potentials for accessing a broader range of alternative involvements than retirees with less education. Higher educated elders exhibit more coping mechanisms with many stressful situations during their life even in the retirement period which reflected assuredly on satisfaction. Similarly, Noone et al $(2013)^{(52)}$ revealed that educational status is a contributory factor to the degree of retirement satisfaction. Wetzel et al $(2016)^{(23)}$ added that poor health condition and limited motivational activities were observed among uneducated retirees in comparison with counterfactual group.

Evidence suggests that planning for life changes becomes very important to individuals as they approach the end of their careers, and this can lead to better postretirement satisfaction and outcomes. The finding of this study revealed that the studied retirees who planned for retirement reported significantly high level of the overall post-retirement satisfaction than those who did not (table 1). Retirement plan usually includes financial, social, recreational, spiritual and leisure activities. This plan is done individually as there is no or inadequate pre-retirement planning programs provided to older adults before retirement transition in Egypt. This result is congruent with the finding of a study done in Egypt (2000) ${ }^{(53)}$ which revealed that the majority of older adults who did not plan for retirement failed to cope with its stressors. Muratore and Earl $(2010)^{(54)}$ added that older adults who attended pre-retirement education gained a positive attitude towards retirement and got better post-retirement fulfillment than those who did not. Moreover, Bader El din et al (2012) ${ }^{(55)}$ revealed a relation between satisfaction to retirement and planning if planning began at least a year before retirement.

In conjunction, formal- phased retirement is a preferred era in retirement program, hopefully to be integrated in Egypt in a broad scene, which encouraged employees to phase into retirement gradually by reducing work hours for a significant period of time prior to full retirement. Flexible work schedules for the older adults, different retirement options and an adequate delay of retirement age are alternative methods serve to bridge the gaps between 
employees, governments and organizations to obtain more flexible labor arrangement and satisfaction. It is important that interventions targeting behavior during this transition assist with identification of contextually salient goals and the use of supported resources to achieve these ends.

\section{Conclusion}

Based on the results of the study, it can be concluded that post-retirement satisfaction is affected by the available resources for the retired persons such as economic or financial, health, social, psychological and spiritual resources. Furthermore, sex particularly males, young old, married persons, and higher level of education affected significantly postretirement satisfaction. Also, upgrading lifestyle pattern and planning ahead for retirement were significant markers for being highly satisfied with retirement. As well, absence of chronic diseases and independence in performing activities of daily living were significant factors in retirement satisfaction. This throw light on the importance of pre-retirement planning.

\section{Recommendations}

Based on the findings of the current study, the following recommendations are suggested:

- Encourage employees to phase into retirement gradually by reducing work hours for a certain period of time (one year) prior the full retirement. This can be achieved through its inclusion in the policy of the different working organizations and labor force. Prior retirement, allow flexible work schedules and provide different retirement options such as part time work or voluntary work.

- Stress the importance of maintaining healthy living through proper nutrition, exercise, avoid risk behaviors and sedentary life, and keep active to maintain physical strength during retirement transition.

- Emphasis the importance of preretirement plan for older adults. The gerontological nurse can play a role in disseminating information about retirement and its effect on individuals' well being and teaching retirees the importance of allocating various resources during the retirement process in order to achieve greater satisfaction, and wellbeing during retirement.

- Raise public awareness about the importance of adopting a holistic view of retirement preparation through mass media. This aims to break down stereotypes that underestimate older people's ability to participate and contribute fully in community life and teach the importance of organizing resources earlier. Also, it helps to orient the retired persons about the available community services that can help them during the retiring period. 
Table (1): Distribution of the retired older adults according to their socio-demographic characteristics and its relation to their life satisfaction

\begin{tabular}{|c|c|c|c|c|c|}
\hline \multirow{2}{*}{ Socio-demographic data } & \multirow{2}{*}{$\mathbf{N}$} & \multicolumn{2}{|c|}{ Life Satisfaction } & \multirow{2}{*}{$\begin{array}{l}\text { Test of } \\
\text { sig. }\end{array}$} & \multirow{2}{*}{$\mathbf{p}$} \\
\hline & & Min. - Max. & Mean \pm SD & & \\
\hline $\begin{array}{l}\text { Age in year } \\
\begin{array}{c}-\quad 60 \text { years- less than } 75 \text { years } \\
-\quad 75 \text { years }-85 \text { yrs }\end{array}\end{array}$ & $\begin{array}{c}143 \\
67\end{array}$ & $\begin{array}{l}27.27-93.94 \\
27.27-66.67\end{array}$ & $\begin{array}{c}57.34 \pm 15.28 \\
32.65 \pm 7.77\end{array}$ & $\begin{array}{c}t= \\
16.074^{*}\end{array}$ & $<0.001^{*}$ \\
\hline \begin{tabular}{|rl} 
Sex & \\
- & Male \\
- & Female \\
\end{tabular} & $\begin{array}{l}106 \\
104 \\
\end{array}$ & $\begin{array}{l}27.27-100.0 \\
27.27-72.73 \\
\end{array}$ & $\begin{array}{l}59.95 \pm 24.05 \\
42.10 \pm 14.86\end{array}$ & $\begin{array}{c}t= \\
6.482^{*}\end{array}$ & $<0.001^{*}$ \\
\hline \begin{tabular}{|c} 
Marital status \\
$-\quad$ Married \\
$-\quad$ Not married
\end{tabular} & $\begin{array}{c}145 \\
65\end{array}$ & $\begin{array}{l}33.33-100.0 \\
27.27-63.64\end{array}$ & $\begin{array}{c}59.27 \pm 20.14 \\
31.54 \pm 9.33\end{array}$ & $\begin{array}{c}\mathrm{t}= \\
14.884^{*}\end{array}$ & $<0.001^{*}$ \\
\hline \begin{tabular}{|l} 
Level of education \\
$-\quad$ Illiterate / Read and write / Basic / \\
$\quad$ secondary/ University. \\
$-\quad$ Post-university education - \\
\end{tabular} & $\begin{array}{r}18 \\
192 \\
\end{array}$ & $\begin{array}{l}27.27-66.67 \\
66.67-100.0 \\
\end{array}$ & $\begin{array}{c}40.57 \pm 14.48 \\
90.91 \pm 9.46\end{array}$ & $\begin{array}{c}t= \\
16.729^{*}\end{array}$ & $<0.001^{*}$ \\
\hline \begin{tabular}{|cl} 
Occupation before retirement \\
- & Employees \\
- & Worker \\
\end{tabular} & $\begin{array}{c}118 \\
92 \\
\end{array}$ & $\begin{array}{c}27.27-100.0 \\
27.27-75.76 \\
\end{array}$ & $\begin{array}{l}60.04 \pm 22.56 \\
39.66 \pm 14.51 \\
\end{array}$ & $\begin{array}{c}\mathrm{t}= \\
7.933^{*}\end{array}$ & $<0.001^{*}$ \\
\hline $\begin{aligned} \text { Income } & \\
- & \text { Enough } \\
- & \text { Not enough }\end{aligned}$ & $\begin{array}{c}53 \\
157\end{array}$ & $\begin{array}{c}33.3-100.0 \\
27.27-90.91\end{array}$ & $\begin{array}{l}77.93 \pm 16.77 \\
42.06 \pm 14.89\end{array}$ & $\begin{array}{c}t= \\
14.683^{*}\end{array}$ & $<0.001^{*}$ \\
\hline \begin{tabular}{|l} 
Presence of chronic diseases \\
$-\quad$ Yes \\
$-\quad$ No
\end{tabular} & $\begin{array}{c}194 \\
16 \\
\end{array}$ & $\begin{array}{c}27.27-93.94 \\
66.67-100.0 \\
\end{array}$ & $\begin{array}{c}47.88 \pm 19.37 \\
90.34 \pm 8.66 \\
\end{array}$ & $\begin{array}{c}t= \\
16.506^{*}\end{array}$ & $<0.001^{*}$ \\
\hline $\begin{array}{l}\text { Ability to perform various activities of } \\
\text { daily living } \\
\begin{array}{l}\text { - Able } \\
-\quad \text { Disable }\end{array}\end{array}$ & $\begin{array}{c}123 \\
87\end{array}$ & $\begin{array}{c}27.27-100.0 \\
27.27-90.91\end{array}$ & $\begin{array}{l}62.87 \pm 20.14 \\
34.48 \pm 10.59\end{array}$ & $\begin{array}{c}t= \\
13.257^{*}\end{array}$ & $<0.001^{*}$ \\
\hline $\begin{array}{l}\text { Pre-retirement planning } \\
-\quad \text { Yes } \\
-\quad \text { No }\end{array}$ & $\begin{array}{c}70 \\
140\end{array}$ & $\begin{array}{l}54.55-100.0 \\
27.27-81.82\end{array}$ & $\begin{array}{l}74.63 \pm 15.60 \\
39.35 \pm 13.49\end{array}$ & $\begin{array}{c}t= \\
16.143^{*}\end{array}$ & $<0.001^{*}$ \\
\hline
\end{tabular}

$\mathrm{t}, \mathrm{p}$ : $\mathrm{t}$ and $\mathrm{p}$ values for Student $\mathrm{t}$-test

*: Statistically significant at $\mathrm{p} \leq 0.05$

Table (2): Distribution of the retired older adults according to their post-retirement resources using Retirement Resources Inventory

\begin{tabular}{|c|c|c|c|c|c|c|c|c|}
\hline \multirow{2}{*}{$\begin{array}{l}\text { Older adults' Post - retirement } \\
\text { resources }\end{array}$} & \multicolumn{2}{|c|}{$\begin{array}{c}\text { Low } \\
\text { Resources } \\
(\text { score }<\mathbf{5 0 \%})\end{array}$} & \multicolumn{2}{|c|}{$\begin{array}{c}\text { Moderate } \\
\text { resources } \\
\text { (score 50 - } \\
<75 \% \text { ) } \\
\end{array}$} & \multicolumn{2}{|c|}{$\begin{array}{c}\text { High resources } \\
(\text { score } \geq 75 \%)\end{array}$} & \multirow{2}{*}{$\begin{array}{l}\text { Total mean } \\
\text { Score }\end{array}$} & \multirow[t]{2}{*}{$\mathbf{P}$} \\
\hline & No. & $\%$ & No. & $\%$ & No. & $\%$ & & \\
\hline $\begin{array}{l}\text { Physical and financial } \\
\text { resources }\end{array}$ & 156 & 74.3 & 27 & 12.9 & 27 & 12.9 & $\begin{array}{c}8.0-37.0 \\
19.56 \pm 7.66\end{array}$ & \multirow{3}{*}{$<0.001^{*}$} \\
\hline Social resources & 142 & 67.6 & 48 & 22.9 & 20 & 9.5 & $\begin{array}{c}9.0-86.0 \\
21.88 \pm 8.97\end{array}$ & \\
\hline $\begin{array}{l}\text { Emotional, cognitive and } \\
\text { motivational resources }\end{array}$ & 112 & 53.3 & 66 & 31.4 & 32 & 15.2 & $\begin{array}{c}19.0-117.0 \\
48.50 \pm 19.13 \\
\end{array}$ & \\
\hline The Overall resources & 143 & 68.1 & 38 & 18.1 & 29 & 13.8 & $\begin{array}{r}41.0-16 \\
89.94 \pm 3\end{array}$ & \\
\hline
\end{tabular}

$\mathrm{p}: \mathrm{p}$ value for ANOVA with repeated measures for comparing between scales

:*Statistically significant at $\mathrm{p} \leq 0.05$ 
Table (3): Relation between availability of resources and post-retirement life-satisfaction

\begin{tabular}{|c|c|c|c|c|c|}
\hline \multirow{2}{*}{ Post-retirement resources } & \multirow{2}{*}{$\mathbf{N}$} & \multicolumn{2}{|c|}{ Life Satisfaction } & \multirow{2}{*}{$\begin{array}{l}\text { Test of } \\
\text { sig. }\end{array}$} & \multirow{2}{*}{$\mathbf{p}$} \\
\hline & & Min. - Max. & Mean \pm SD. & & \\
\hline \multicolumn{6}{|c|}{ Physical and financial resources } \\
\hline Low $($ score $<50 \%)$ & 156 & $27.27-69.70$ & $41.22 \pm 13.73$ & \multirow{3}{*}{$\begin{array}{c}\mathrm{F}= \\
210.297^{*}\end{array}$} & \multirow{3}{*}{$<0.001^{*}$} \\
\hline Moderate (score $50-<75 \%$ ) & 27 & $42.42-90.91$ & $67.68 \pm 10.86$ & & \\
\hline High (score $\geq 75 \%$ ) & 27 & $72.73-100.0$ & $91.69 \pm 5.42$ & & \\
\hline \multicolumn{6}{|l|}{ Social resources } \\
\hline Low (score $<50 \%)$ & 142 & $27.27-93.94$ & $40.10 \pm 14.75$ & \multirow{3}{*}{$\begin{array}{c}\mathrm{F}= \\
154.993^{*}\end{array}$} & \multirow{3}{*}{$<0.001^{*}$} \\
\hline Moderate (score $50-<75 \%$ ) & 48 & $51.52-100.0$ & $67.61 \pm 13.08$ & & \\
\hline High (score $\geq 75 \%$ ) & 20 & $57.58-93.94$ & $89.70 \pm 8.54$ & & \\
\hline \multicolumn{6}{|c|}{$\begin{array}{l}\text { Emotional, cognitive and motivational } \\
\text { resources }\end{array}$} \\
\hline Low (score $<50 \%$ ) & 112 & $27.27-60.61$ & $34.06 \pm 8.23$ & \multirow{3}{*}{$\begin{array}{c}\mathrm{F}= \\
534.859^{*}\end{array}$} & \multirow{3}{*}{$<0.001^{*}$} \\
\hline Moderate (score $50-<75 \%$ ) & 66 & $45.45-93.94$ & $62.21 \pm 7.74$ & & \\
\hline High (score $\geq 75 \%$ ) & 32 & $33.33-100.0$ & $87.88 \pm 12.48$ & & \\
\hline \multicolumn{6}{|l|}{ Overall resources } \\
\hline Low $($ score $<50 \%)$ & 143 & $27.27-63.64$ & $39.25 \pm 12.42$ & \multirow{3}{*}{$\begin{array}{c}\mathrm{F}= \\
257.752^{*}\end{array}$} & \multirow{3}{*}{$<0.001^{*}$} \\
\hline Moderate (score $50-<75 \%$ ) & 38 & $33.33-93.94$ & $66.67 \pm 10.89$ & & \\
\hline High (score $\geq 75 \%$ ) & 29 & $57.58-100.0$ & $89.24 \pm 9.29$ & & \\
\hline
\end{tabular}

F,p: $\mathrm{F}$ and $\mathrm{p}$ values for ANOVA test

*: Statistically significant at $\mathrm{p} \leq 0.05$ 
Table (4): Distribution of the retired older adults according to their life-satisfaction level post- retirement using Retirement Satisfaction Inventory

\begin{tabular}{|l|c|c|}
\hline Level of life satisfaction among retired older adults & $\begin{array}{c}\text { No. } \\
(\mathbf{n = 2 1 0})\end{array}$ & $\%$ \\
\hline Low satisfaction (score <16) & 103 & 49.0 \\
Moderate satisfaction (score 16-24) & 75 & 35.7 \\
High satisfaction (score >24) & 32 & 15.2 \\
\hline Total score & $9.0-33.0$ \\
Min. - Max. & $16.87 \pm 7.23$ \\
Mean \pm SD. & $27.27-100.0$ \\
\hline Percent score & $11 \pm 21.89$ \\
Min. - Max. & \multicolumn{2}{|c|}{} \\
Mean \pm SD. & \multicolumn{2}{|l}{} \\
\hline
\end{tabular}

Table (5): Relation between lifestyle pattern of retired older adults and post retirement lifesatisfaction

\begin{tabular}{|l|c|c||}
\hline \multirow{2}{*}{ Domains of the Lifestyle pattern of the retired older adults } & \multicolumn{2}{|c|}{$\begin{array}{c}\text { Life Satisfaction of the } \\
\text { retired older adults }\end{array}$} \\
\cline { 2 - 3 } & $\mathbf{r}$ & $\mathbf{p}$ \\
\hline Physical functioning & $0.834^{*}$ & $<0.001^{*}$ \\
\hline Social functioning & $0.854^{*}$ & $<0.001^{*}$ \\
\hline Economic functioning & $0.663^{*}$ & $<0.001^{*}$ \\
\hline Psychological functioning & $0.783^{*}$ & $<0.001^{*}$ \\
\hline Spiritual functioning & $0.227^{*}$ & $0.001^{*}$ \\
\hline Recreational/Motivational functioning & $0.817^{*}$ & $<0.001^{*}$ \\
\hline Overall lifestyle pattern & $0.879^{*}$ & $<0.001^{*}$ \\
\hline
\end{tabular}

r: Pearson coefficient $*$ : Statistically significant at $\mathrm{p} \leq 0.05$ 


\section{References}

1. Lawal A, Idemudia E. Life satisfaction in retirement: The direct influence of gender, self-esteem and health locus of control in southwestern parts of Nigeria. Ethno Med 2017; 11(4): 302- 10.

2. Heybroek L, Haynes M, Baxter J. Life satisfaction and retirement in Australia: A longitudinal approach. Work Aging and Retirement 2015; 1(2): 166-80.

3. Zantinge EM, an-den Berg M, Smit HA, Picavet HS. Retirement and a healthy lifestyle: Opportunity or pitfall? A narrative review of the literature. Eur. J. Pub. Health 2014; 24:433-39.

4. Wang M, Henkens K, Van Solinge H. Retirement adjustment: A review of theoretical and empirical advancements. American Psychologist 2011; 66(3): 20413.

5. Heaven B, Brown LJ, White M, Errington L, Mathers JC, Moffatt S. Supporting wellbeing in retirement through meaningful social roles: Systematic review of intervention studies. Milbank Q 2013; 91(2): 222-87.

6. Ryser VA, Wernli B. How does transitioning into retirement impact the individual emotional system? Evidence from the Swiss context. Advances in Life Course Research 2017; 32: 42-54.

7. Stenholm S, Vahtera J. Does retirement benefit health? Preventive Medicine 2017; 100: 294-95.

8. Spord J, Olds T, Brown W, Burton N, Van Uffelen J, Ferrar K, Maher C. Changes in use of time across retirement: A longitudinal study. Maturitas 2017; 100: 70-6.

9. Deniera N, Cloustonb S, Richardsc M, and Hoferd SM. Retirement cognition: A life course view. Advances in Life Course Research 2017; 31: 11-21.

10. Chung S, Domino ME, Stearns SC. The effect of retirement on weight. J Gerontol B Psychol Sci Soc Sci 2009; 64 (5): 656- 65.

11. Myllyntausta S, Salo P, Kronholm E, Pentti J, Kivimaki M, Vahtera J, Stenholm S.
Changes in sleep difficulties during the transition to statutory retirement. Sleep 2018; 41(1): 182.

12. Van - Solinge H, Henkens K. Adjustment to and satisfaction with retirement: Two of a kind? Psychology and Aging. 2008; 23(2): 422-34.

13. Banerjee S. Trends in retirement satisfaction in the United States: Fewer having a great time. Employee Benefit Research Institute 2016; 37(4):1-12.

14. Topa G, Jiménez I, Valero E, Ovejero A. Resource loss and gain, life satisfaction, and health among retirees in Spain. J Aging Health 2017; 29(3): 415-36.

15. Heaven B, O'Brien N, Evans EH, White M, Meyer TD, Mathers JC, and Moffatt S. Mobilizing resources for well-being: Implications for developing interventions in the retirement transition. Gerontologist 2016; 56(4): 615-29.

16. Burr A, Santo JB, Pushkar D. Affective wellbeing in retirement: The influence of values, money, and health across three years. Journal of Happiness Studies 2011; 12(1): 17-40.

17. Leung CSY, Earl JK. Retirement Resources Inventory: Construction, factor structure and psychometric properties. Journal of Vocational Behavior 2012; 81(2): 171-82.

18. Lahti J, Laaksonen M, Lahelma E. Changes in leisure-time physical activity after transition to retirement: a follow-up study. Int J Behav Nutr Phys Act 2011; 8:1-36.

19. Asebedo AD, Seay MC. Positive psychological attributes and retirement satisfaction. Journal of Financial Counseling and Planning 2014; 25(2): 16173.

20. Elder HW, Rudolph PM. Does retirement planning affect the level of retirement satisfaction? Financial Services Review 1999; 8(2): 117-27.

21. Gaied JY. Coping strategies to retirement of community-dwelling older adults. Unpublished Master Dissertation. Faculty of Nursing, University of Alexandria, 2014. 
22. Feldt T, Hyvönen K, Oja-Lipasti T, Kinnunen U, Salmela-Aro K. Do work ability and job involvement channel later personal goals in retirement? An 11-year follow-up study. International Archives of Occupational and Environmental Health 2012; 85(5): 547-58.

23. Wetzel M, Huxhold O, Tesch-Römer C. Transition into retirement affects life satisfaction: Short- and long-term development depends on last labor market status and education. Social Indicators Research: An International and Interdisciplinary Journal for Quality of Life Measurement 2016; 125(3): 991-1009.

24. Floyd FJ, Haynes SN, Doll ER, Winemiller D, Lemsky C, Burgy TM, Werle M, Heilman, N. Assessing retirement satisfaction and perceptions of retirement experiences. Psychology and Aging 1992; 7(4): 609-21.

25. Ejechi EO, Ogege SO. Quality of life of female public service retirees in a Nigerian setting. Journal of Social and Management Sciences 2016; 11(1): 62-71.

26. Siguaw JA, Sheng $X$, Simpson PM. Biopsychosocial and retirement factors influencing satisfaction with life: New perspectives. The International Journal of Aging and Human Development 2017, DOI: https://doi.org/10.1177/00915016685833.

27. Fadila D, Alam R. Factors affecting adjustment to retirement among retirees' elderly persons. Journal of Nursing Education and Practice 2016; 6(8): 112-22.

28. Barnett I, Van-Sluijs E, Ogilvie D. Physical activity and transitioning to retirement: a systematic review. Am J Prev Med 2012; 43(3):329-36.

29. Barnett I, Van-Sluijs E, Ogilvie D, Wareham NJ. Changes in household, transport and recreational physical activity and television viewing time across the transition to retirement: longitudinal evidence from the EPIC-Norfolk cohort. J. Epidemiol. Community Health 2014; 68(8): 747-53.
30. Zhu R. Retirement and its consequences for women's health in Australia. Soc. Sci. Med 2016; 163:117- 25 .

31. Oshio T, Kan M. The dynamic impact of retirement on health: Evidence from a nationwide ten-year panel survey in Japan. Preventive Medicine 2017; 100: 287-93.

32. Denier N, Clouston S, Richards M, Hofer S. Retirement and cognition: A life course view. Advances in Life Course Research 2017; 31: 11-21.

33. Bonsang E, Adam S, Perelman S. Does retirement affect cognitive functioning? Journal of Health Economics 2012; 31(3): 490-501.

34. Byles JE, Vo K, Forder P, Thomas L, Banks E, Rodgers B, Bauman A. Gender, mental health, physical health and retirement: a prospective study of 21,608 Australians aged 55-69 years. Maturitas 2016; 87: 40-8.

35. David D, Rashad I, Spasojevic J. The effects of retirement on physical and mental health outcomes. South. Econ. J. 2008; 75(2): 497-523.

36. Regan K, Intzandt B, Swatridge K, Myers A, Roy E, Middleton LE. Changes in physical activity and function with transition to retirement living: A pilot study. Canadian Journal on Aging 2016; 35(4): 526- 32.

37. McDonald S, O'Brien N, White M, Sniehotta FF. Changes in physical activity during the retirement transition: A theorybased, qualitative interview study. Int $\mathrm{J}$ Behav Nutr Phys Act 2015; 12: 25.

38. Brady PJ. Measuring retirement resource adequacy. Journal of Pension Economics and Finance 2010; 9(2): 235-62.

39. Ding D, Grunseit AC, Chau JY, Vo K, Byles J, Bauman AE. Retirement-a transition to a healthier lifestyle? Evidence from a large Australian study. Am. J. Prev. Med 2016; 51(2):170-78.

40. Lowis MJ, dwards AC, Burton M. Coping with retirement: well-being, health, and religion. The Journal of Psychology 2009, 143(4), 427-48. 
41. Social Security Administration. Behavioral and psychological aspects of the retirement decision. Social Security Bulletin 2011; 71(4): 15-32.

42. Potocnik K, Tordera N, Peiró JM. Truly satisfied with your retirement or just resigned? Pathways toward different patterns of retirement satisfaction. Journal of Applied Gerontology 2013; 32(2): 16487.

43. Mezuk B, Ratliff S, Concha JB, Abdou CM, Raffetry J, Lee H, Jackson JS. Stress, self-regulation, and context: Evidence from the health and retirement survey. SSM Population Health 2017; 3: 455- 63.

44. Saeed F, Bokharey IZ. Gender differences, life satisfaction, its correlate and death anxiety in retirement. Journal of Psychology and Clinical Psychiatry 2016; 5(2): 00280.

45. Alavinia SM, Burdorf A. Unemployment and retirement and ill-health: a cross sectional analysis across European countries. Int Arch Occup Environ Health 2008; 82(1): 39-45.

46. Bajalia J. Living longer is the greatest retirement risk for women. Daily Views. http://www.nydailynews.com/lifestyle/living-longer-greatest-retirement-riskwomen-article-1.2947645. (Retrieved on: January 16, 2017).

47. Mary P, Ming L, Lee C. The resources and life satisfaction of retired women in Malaysia. Asia Pacific Journal of Advanced Business and Social Studies 2016; 2(1): 212-21.

48. Brooks R. Even in retirement men and women are different. USA Insurance and Annuity Association Report: The Washington post 2016. https://www.washingtonpost.com/news/getthere/wp/2016/05/02/. (Retrieved on: May 2, 2016).

49. Kubicek B, Korunka C, Raymo JM, Hoonakker P. Psychological wellbeing in retirement: the effects of personal and gendered contextual resources. J Occup Health Psychol. 2011; 16(2): 230-46.

50. Kerr G, Armstrong $\mathrm{S}$. The bridge to retirement: Older workers' engagement in post-career entrepreneurship and wage-andsalary employment. Journal of Entrepreneurship 2011; 20(1): 55-76.

51. Bozoglan B. Spousal intrusion as a predictor of wives' marital satisfaction in their spouses' retirement. Psychol Rep 2015; 116(3); 921-35.

52. Noone J, O‘Loughlin $\mathrm{K}$, Kendig $\mathrm{H}$. Australian baby boomers retiring early“: Understanding the benefits of retirement preparation for involuntary and voluntary retirees. Journal of Aging Studies 2013; 27 : 207-17.

53. Ibrahim N. The family and the elderly. review article. Assistant professor. Alexandria: Alexandria University, Faculty of Nursing, 2000.

54. Muratore AM, Earl JK. Predicting retirement preparation through the design of a new measure. Australian Psychologist 2010; 45(2): 98-111.

55. Bader El-din S, Mohamed G, Abo El Maged M. Pre-retirement Education Program for Faculty of Nursing Employees in El-Minia University. Journal of American Science 2012; 8(2): 188. 